\title{
El rastro de los pecaríes. Variaciones míticas, variaciones cosmológicas e identidades étnicas en la etnología pano
}

\section{Oscar Calavia Sáez}

\section{CpenEdition \\ Journals}

Edición electrónica

URL: http://journals.openedition.org/jsa/1846

DOI: $10.4000 /$ jsa. 1846

ISSN: 1957-7842

\section{Editor}

Société des américanistes

\section{Edición impresa}

Fecha de publicación: 1 enero 2001

Paginación: 161-176

ISSN: 0037-9174

\section{Referencia electrónica}

Oscar Calavia Sáez, «El rastro de los pecaríes. Variaciones míticas, variaciones cosmológicas e identidades étnicas en la etnología pano », Journal de la Société des américanistes [En línea], 87 | 2001, Publicado el 17 noviembre 2005, consultado el 10 julio 2020. URL : http://journals.openedition.org/ jsa/1846 ; DOI : https://doi.org/10.4000/jsa.1846

Este documento fue generado automáticamente el 10 julio 2020.

(c) Société des Américanistes 


\title{
El rastro de los pecaríes. Variaciones míticas, variaciones cosmológicas e identidades étnicas en la etnología pano
}

\author{
Oscar Calavia Sáez
}

1 En los últimos cinco años, el totemismo y el animismo, conceptos que solíamos relegar a la historia remota de la antropología, han mostrado un cierto vigor e incluso una inesperada capacidad de procrear. Nace de ellos, en el centro de un debate sobre el binomio naturaleza/cultura, una acepción particular de perspectivismo de gran predicamento en la actual etnología brasileña (Viveiros de Castro 1996). Al margen de ese debate, el «renacer » del totemismo y el animismo invita a examinar también la relación entre factores que siempre anduvieron amalgamados en el crisol del pensamiento primitivo: mitología, chamanismo, cosmología, ideologías del parentesco. Este artículo intenta contribuir a ese examen siguiendo el rastro de un animal que en la bibliografía referida (véase especialmente Lima 1996) resalta como ejemplarmente totémico, animista, chamánico, mítico y social: el cerdo salvaje, o más exactamente su especie más conocida: Tayassu albirostris, que en el presente texto designaremos con el término más corriente en las lenguas europeas, "pecarí » - en portugués de Brasil, queixada, y huangana en el español del Perú. Los pecaríes son, en las culturas de las tierras bajas de Sudamérica, una metáfora extremadamente frecuente de la sociedad humana, por su gregarismo, por su aptitud para la defensa común - que hace de ellos uno de los animales más peligrosos para el cazador - y eventualmente por otros atributos como su sujeción a un jefe. No se puede extrañar que la mitología a ellos referida sea sumamente sensible a las variaciones sociológicas de los grupos indígenas ${ }^{1}$.

Los yaminawa del Río Acre ${ }^{2}$ narran dos mitos que tienen los cerdos salvajes como actores principales. El más popular es Yawavide («El que se volvió pecarí »), del que doy aquí un extenso resumen:

«Esto era un hombre extremadamente panemo, incapaz de cazar. En su casa se pasaba hambre, a no ser que sus cuñados le ofreciesen algún pedazo de lo que ellos 
cazaban. Un buen día, cansado de esa vida, le pidió a uno de ellos que le enseñase el modo de traer una buena queixada a casa. El cuñado le dio indicaciones precisas de un lodazal donde sin duda las encontraría. El hombre salió temprano, y en efecto encontró allí un grupo de queixadas. Disparó sus flechas una tras otra ; pero aunque siempre daba en el blanco, los animales no caían. Fue persiguiéndolos selva adentro, dispuesto a no volver de manos vacías, hasta que se hizo de noche y no tuvo cómo volver de ningún modo. Muerto de frío y de miedo, se refugió entre las grandes raíces de una samaúma, y allí estaba cuando oyó pasos y voces humanas que decían "el rastro va por aquí", "no puede estar lejos", "mira, ahí está escondido". Se vió entonces ante un grupo de hombres que le preguntaban: "primo, ¿eras tú el que nos tiraba flechas hoy por la mañana?". "No - dijo él - no os ataqué a vosotros, sino a un grupo de queixadas". "Éramos nosotros, primo. Anda, vente con nosotros, debes estar con frío y con hambre". Sin otra opción, el hombre fue con los desconocidos y llegó a una aldea grande y hermosa en que muchas personas se curaban de las heridas de sus flechas, que pudo reconocer. Pero los extraños eran amigables. Le ofrecieron bebida, aunque era un cuenco de lama. "Yo no bebo eso: eso es lo que beben los pecaríes, no los seres humanos". "No lo estás viendo bien, primo" le dijeron, y exprimieron en sus ojos una planta; entonces vió que el cuenco tenía chicha sabrosa. "Tendrás hambre" le dijeron, ofreciéndole un puñado de paxiubinha. "Eso es comida de queixada, no de ser humano" repuso. "No lo sabes ver" y de nuevo gotearon en sus ojos el zumo de aquella planta. Vió entonces que era buena carne asada. Aquella aldea de los pecaríes humanos era en resumen un excelente lugar al que pronto se habituó. Se casó con una de las mujeres-queixada y tuvo varios hijos con ella. Pero en su aldea de origen no se olvidaban de él. Al día siguiente de su desaparición fueron tras sus huellas y pensaron que los pecaríes lo habían devorado. Mucho después un cazador vió un rebaño de queixadas huyendo, y percibió entre ellas un hombre, encorvado y con el espinazo lleno de pelos. Se lo dijo al hermano mayor del desaparecido, y éste supuso al momento que su hermano se había quedado a vivir con los animales. Decidió rescatarlo y con la ayuda de los otros tendió una trampa y consiguió atraparlo. El hombre semitransformado se debatía y gruñía como un cerdo salvaje, pero al cabo pudo comunicarse con sus parientes humanos y contarles su aventura, y por fin les propuso una gran cacería. Él conocía los caminos y los escondites de los pecaríes y los reveló a los cazadores. La expedición fue un éxito: el hombre-queixada dirigía la operación gritando: "ése era mi suegro, dispara!", “ésa era mi mujer, dispara", "ése era mi cuñado", etc. Se celebró entonces un gran banquete, en el que el transformado no participaba, porque su mujer-queixada le había advertido que si alguna vez volviese a comer queixada moriría. Pero no pudo aguantar por mucho tiempo el aroma de la carne asada. Acabó probando un bocado, y en seguida murió. »

El relato es una ilustración inmejorable de lo que Viveiros de Castro (1996) ha definido como una cosmología perspectivista. Todos los seres dotados de espíritu forman colectivos equivalentes en cuanto a la cultura (culinaria, habitación o conceptos de parentesco son los mismos) pero diferenciados por una « ropa » natural - las " pieles » del pecarí, el jaguar, el hombre o tal o cual vegetal. Es la mirada de cada uno lo que ordena el conjunto: el hombre puede ser visto como un jaguar por los pecaríes y como un pecarí por los jaguares, de modo que la condición de sujeto u objeto - congelada en la acepción naturalista de los términos cultura y naturaleza - resulta reversible y siempre dependiente de un punto de vista. Tal cosmología puede multiplicar su potencia en el caso pano con una identificación entre el espíritu y la pupila del ojo y con la omnipresencia en el chamanismo o los mitos de plantas capaces de modificar la visión (Calavia 2000). La aventura de Yawavide muestra también cómo el canibalismo puede ser entendido como un subconjunto de esa cosmología - guerra y caza son perfectamente intercambiables. 
4 Pero pasemos al otro relato, también recogido entre los yaminawa, que describe una aventura parcialmente afín a la del primero:

« Un grupo se había instalado en un campamento a la orilla de un lago, cazando y pescando. Una tarde, la mujer del jefe estaba haciendo chicha, y necesitaba mucho fuego. Fue a buscar leña y cerca del lago oyó el canto de un pájaro grande: "ca, ca, ca...". "Debe ser un inhambú", pensó. Pero se trataba de un yawayawaiká3. Miró alrededor y encontró un nido lleno de huevos. "No voy a poder cogerlos todos yo sola”, pensó, y llamó a las otras mujeres y llevaron todos los huevos, que fueron comiendo mientras esperaban a los hombres. Cuando ellos llegaron, cargados de pescado, ella le mostró a su marido lo que había encontrado, que se admiró: "Con eso da para comer dos días". De modo que todos los hombres comieron también, conversando mientras moqueaban el pescado, hasta que llegó la hora de dormir. Por la noche, una niña se despertó llorando. “¿Qué pasa?” fue a preguntar su padre, el cacique, pero en lugar de las palabras le salió un gruñido: “Ui, ui, ui!" porque se había convertido en queixada, al igual que la niña en el momento en que lloró. “¿Qué ha pasado?” fue a preguntar la madre, pero la voz le salió diferente, ya no era voz humana sino gruñido de queixada. Los vecinos fueron a ver qué pasaba, preguntaban pero no conseguían hablar. Todos se habían vuelto queixadas, excavaron todo el lugar en que estaban, lo convirtieron en un lodazal y se fueron. Entonces otro grupo de gente que pasó por allí lo encontró todo revuelto y lleno de barro. “¿ué ha pasado aquí?” se preguntaron, y buscando pistas sólo encontraron las cáscaras de los huevos. "Nunca había visto un huevo como ése" decían algunos, mientras olían las cáscaras. “¿Será que se han vuelto queixadas por comerlos?” y decidieron volver a la aldea a contar lo que había pasado. Pero en el camino los que habían olido las cáscaras se transformaron en caetetus. No quedó más que un hombre y una mujer, que siguieron camino. Pero poco antes de llegar sopló el viento y la corteza de un paxiubão les cayó encima, y dieron un grito: en ese momento la voz ya les salió diferente, porque se habían convertido en venados. »

5 No se pretende aquí sino espigar algunos elementos de un conjunto de mitos cuyo análisis llevaría muy lejos. Para empezar, cabe comentar que, aparte de los pecaríes, el caetetu (Tayassu tayassu, una especie menor en tamaño y que no se presenta en grandes bandos como las queixadas) aparece también fugazmente como su versión débil ${ }^{4}$. La caracterización del caetetu como residuo o sub-expresión del pecarí remite al contraste entre la plenitud del grupo y las familias dispersas - protagonistas de numerosos mitos que tematizan su desvalimiento, o su desvío de los cánones culturales. Llama la atención, por otro lado, que dos narraciones tan próximas en cuanto al tema se den por separado, sobre todo cuando mitologías muy próximas a la yaminawa, como veremos más tarde, establecen nexos entre ellas o combinan sus episodios. Ambos relatos ofrecen algunas claves para la interpretación de los mitos de este pueblo poco dado a la exégesis.

Los pecaríes: sociología y esoterismo

Los pecaríes - yawa - poseen una serie de significados bien conocidos en la sociología local. Forman, para empezar, un etnónimo: los yawanawa, o gente-pecarí, son los parientes próximos de los yaminawa. Aparte del grupo que lleva ese nombre en el Río Gregorio - al cual nos referiremos largamente, pero que no mantienen relaciones próximas con los yaminawa - son yawanawa también los habitantes de una aldea en la orilla boliviana del Río Acre ${ }^{5}$. Estos yawanawa son los copartícipes matrimoniales más comunes de los yaminawa, por lo cual no es sorprendente que algunas versiones presenten a los yawanawa como una mitad exogámica (la otra mitad sería la Xixinawa de xixi, coatí blanco) del pueblo yaminawa. Quien esté familiarizado con la literatura sobre grupos pano sabe que en la cuenca del Juruá-Purús se encuentra una pluralidad 
casi infinita de etnónimos formados con el sufijo -nawa y una raíz que generalmente corresponde al nombre de un animal. Esos etnónimos no corresponden a lo que solemos llamar etnias o tribus: más bien forman una trama clasificatoria que puede subdividir cada grupo hasta un nivel individual ${ }^{6}$, pero que también da nombre a las unidades políticas locales, constantemente fragmentadas y recombinadas entre sí, en un contexto de considerable homogeneidad lingüística y cultural. El sistema de etnónimos - que tiene sus equivalentes a todo lo ancho del área pano, y también en los conjuntos etnolingüísticos vecinos ${ }^{7}$ - da al mapa étnico una cierta estabilidad de nombre, a la vez que multiplica dentro de cada grupo las posibles líneas de fractura. Debemos añadir que, especialmente en Brasil, el rótulo yaminawa agrupa al conjunto de los pueblos organizados por esa peculiar constitución.

7 Los etnónimos -nawa suelen incluir alguna connotación proverbial: en el caso de las queixadas, su nomadismo. Una mujer xixinawa, en un canto de lamentación, atribuía la inestabilidad de su hogar a la raíz -pecarí (yawareko) de su marido, siempre dispuesto a arrastrar a su familia en mudanzas malaventuradas de una aldea a otra, o en dirección a la ciudad. Pero pude encontrar también un discurso más esotérico en que los pecaríes (yawandiwo) aparecían como uno de cuatro grandes grupos (kaiwo) ${ }^{8}$ en que los yaminawa estarían divididos, siendo los otros rwandiwo, dwawakewo y xapandiwo. La personalidad de esos kaiwo resulta sugestiva: pecaríes (yawandiwo), animales del interior de la selva (rwandiwo), animales del fondo del agua (dwawakewo) y pájaros que ocupan la parte más alta de los árboles (xapandiwo). Cada uno de los kaiwo es una unidad consanguínea que, aparte de prohibir el matrimonio entre sus miembros humanos, establece analogías entre éstos y sus socios animales. Así los rwandiwo humanos tendrían el olor penetrante y la cara «fea" del jaguar o el gambá, los dwawakewo la visión penetrante que se necesita para moverse en aguas turbias. Los parientes humanos deberían abstenerse de comer la carne de los parientes animales (mi informante evitaba cuidadosamente comer mandí, un pez muy común en la dieta yaminawa); los animales por su parte corresponderían con una garantía de no-agresión, y de venganza contra aquellos congéneres que la transgrediesen (se me dio el ejemplo de las rayas que aparecen muertas en las playas, acribilladas por sus congéneres por el delito de haber aguijoneado a un pariente humano). Palmariamente totémica, esta clasificación cuatripartita parecía corresponder a las omnipresentes mitades pano, aunque en una versión más potente y compleja ${ }^{9}$, lo que no dejaba de ser una proeza, dado el consenso general que reina entre indigenistas, etnólogos e indios acerca de la disgregación cultural yaminawa.

8 El estatuto de este « cristal » etnográfico me pareció durante mi investigación de campo muy dudoso. Tras algunas descripciones extremadamente ricas del dualismo pano, que lo presentaban como una forma sociológica y simbólicamente fuerte (Deshayes y Keifenheim 1982 ; Kensinger 1995, pp. 149-156), los especialistas habían dado versiones progresivamente escépticas, que lo desalojaban de la sociología y lo convertían en un artefacto clasificatorio cada vez más general y abstracto (Townsley 1989 ; Erikson 1993), $\mathrm{y}$, en fin, cada vez menos presente en la vida cotidiana. Los yaminawa brasileños resumían y radicalizaban ese trayecto: su versión del dualismo parecía extremamente fuerte, pero también totalmente ficticia. Ningún yaminawa, por muy versado que fuese en las tradiciones, sabía nada de ellas, ni conseguía tan siquiera identificar el tema, fuera de los dos jefes del grupo con los que sucesivamente traté ${ }^{10}$. Al primero debo la exposición anterior. El segundo, aunque no sabiendo describir el sistema tal como lo acabo de exponer, reafirmó su validez cuando ya tendía a interpretarlo como una 
muestra del ingenio etnológico del primero. "Todos saben de éso », me dijo, « es de éso que tratan los mitos».

9 Efectivamente, los mitos tratan de éso, aunque me costara un tanto reconocerlo. La mitología yaminawa se ocupa casi exclusivamente de transformaciones que alternan lo humano y las más diversas variedades de lo animal, y de los peligros inherentes a esas transformaciones o encuentros: matrimonios entre humanos y animales que acaban en divorcios belicosos o en la devoración de alguno de los cónyuges, las eternas reglas caprichosas de los cuentos de hadas siempre rotas en el momento más inoportuno, etc. Aunque la afinidad sea el tipo de relación más común en estas historias (txai/tsawe bibiki $=\operatorname{primo}(\mathrm{a}) /$ cuñado(a) - esposo(a) es un término que se oye constantemente) no faltan tampoco las relaciones de consanguinidad inter-especies, de modo que la opinión del jefe 2, calificando las cuatro secciones del jefe 1 como un comentario de los mitos, tenía fundamento ${ }^{11}$. Pero también serias limitaciones. En primer lugar, los demás yaminawa no parecían interesarse por vincular mitos y etnónimos, una operación que sería fácil en el caso que nos ocupa. Aunque pasásemos mucho tiempo tratando de pueblos con nombre de animales y de pueblos que se transformaban en animales, no recuerdo que lo uno se ligase con lo otro en ningún momento: los terrenos de la historia y del mito no parecían mezclarse. El que fueran los jefes los únicos dispuestos a dar algún paso tímido en este sentido no era de extrañar - un buen jefe yaminawa pasa el día intentando poner orden en la vida del grupo. Por otro lado, si esa opción clasificatoria podía permanecer latente en la mitología a la espera de alguien que quisiera activarla, resultaba mucho más visible otra opción, sugerida por relatos como Yawavide, que tematizaban la interacción entre clases y su inestabilidad, y que, como veremos, sería de más interés para un chamán que para un jefe. En otras palabras, reinaba entre los yaminawa un equilibrio desigual entre un vector animista y otro totémico, adscritos respectivamente a la metamorfosis y a la clasificación ${ }^{12}$.

Extensiones

Para continuar este análisis se hace necesario seguir la pista de estos mitos en la vecindad etnográfica de los yaminawa. ¿Cómo no comenzar con los Yawanawa, que tienen como epónimo el animal que aquí nos ocupa? Una versión recogida por M. Carid Naveira (1999, pp. 172-174) dice así:

«Dos jefes con sus respectivos grupos deciden ir juntos a una cacería. Acampan junto a un río. Un hombre encuentra un nido con un solo huevo; vuelve varias veces y va encontrando cada vez más: dos, tres, hasta diez huevos. Los distribuye partiéndolos en pedazos pero algunos se quedan sin comer. Va de nuevo al nido (cuyo dueño nunca se deja ver ${ }^{13}$ ) y lo encuentra lleno, pero aún así los huevos alcanzan sólo para la mitad del grupo. Busca el nido una última vez y de nuevo lo encuentra lleno; puede dar así a todos los que se habían quedado sin comer. Solamente dejaron de comer una mujer que no quería casarse con nadie, a quien no quisieron darle nada, y dos jóvenes que estaban fuera cazando y que volvieron más tarde. Al hacerse de noche todos guardaron silencio para oír el canto del pájaro cuyos huevos habían comido. Cantaron dos, hembra y macho: la primera cantaba “yawa, yawa, yawa...” y el segundo respondía "makutchu, makutchu...”. Dijo el jefe: “¿habéis oído? Hemos comido los huevos del pájaro yawayawa iká, vamos a volvernos pecaríes". Y así fue: por la noche una niña fue a llorar pero gruñió como un pecarí, y cuando quisieron hablar, todos lo hicieron con la lengua de los pecaríes. Comenzaron a devorar todo su alimento, a derramarlo, ensuciándose y ensuciándolo todo. La mujer que no había comido huevo no se transformó, y se subió al techo de la cabaña, mirándolo todo.

En cuanto se transformaron, algunas de aquellos pecaríes salieron hacia donde el 
sol se pone, sin participar del festín. Esos son los kushi yawa, que siempre andan así. Otros salían pero volvían al momento diciendo: "me he dejado mi lanza", "me he dejado mi pendiente", "me he dejado mi collar", y aprovechaban para comer todo lo que había en el campamento. Son los yuyu yawa, que siempre vuelven a comer lo que han plantado y por eso nunca andan lejos.

Los dos chicos que habían salido de nuevo a cazar volvieron y se lo encontraron todo en aquel estado. Encontraron las cáscaras de los huevos y las olieron. Cuando iban hacia la aldea para contar a todos lo que había pasado vieron caer la palma de un paxiubão con mucho ruido, y cuando se apartaron gritando se tansformaron en caetetu y venado. Sólo la mujer que no quería casar llegó a la aldea y relató lo que había visto. Aunque fueran sus parientes, pensaron: "se han transformado, ahora son caza". Y desde entonces los mataron y los comieron. "

11 La versión yawanawa confirma o hace visibles algunos trazos de la anterior. Por ejemplo, la constante antífona entre el conjunto del grupo y un fragmento de este. El campamento de caza/pesca es uno de los polos de la variabilidad estacional de muchas sociedades amazónicas; a la aldea más o menos compacta de la estación de las lluvias (escenario de tensiones y de la política que ellas exigen) se opone la libertad de los campamentos familiares dispersos de la época seca. Pero la versión yawanawa se caracteriza por una definición mucho más detallista del proceso de origen del pecarí. La recolección y distribución de los huevos se lleva a cabo por etapas: primero en una lenta progresión de uno hasta diez; después hasta llegar a la mitad; finalmente, abasteciendo de un golpe a la otra mitad (quedando las cáscaras que serán olidas por los descarriados). Los pecaríes resultantes también son discriminados, en función de un trayecto « cíclico » al parecer asociado a un pecarí « más débil » o más doméstico y un trayecto «lineal» que parece corresponder al pecarí en su máxima potencia. En la versión yawanawa hay, en fin, un elemento totalmente nuevo en apariencia: la muchacha cuya resistencia al matrimonio la conserva en el lado humano. Es necesario en este punto traer a colación una versión kaxinawá del mito ${ }^{14}$ :

«Una muchacha irrita a toda su familia con su negativa a casarse. Sus parientes preparan una gran olla de frutos de pamá, que toman, y mientras ella duerme en una hamaca tendida en lo alto de la cabaña se transforman en queixadas y se van dejándola atrás. La chica se desespera al encontrarse sola, pero poco después encuentra un niño muy pequeño en una caja de tabaco colgada del techo. Lo cuida y lo alimenta, durmiendo con él en la hamaca. El niño crece aceleradamente ; anda al primer día, practica con sus flechas en los siguientes y no tarda mucho en mantener relaciones sexuales con la muchacha. Tienen descendencia, y el joven salido de la casa va a cazar, siendo su primera presa el padre de su esposa, ahora convertido en queixada » (Abreu 1941, líneas 2041-2088).

12 En una versión posterior y más literaria (D’Ans 1975, pp. 107-112), el relato continúa con el matrimonio entre los hijos de esta pareja. Finalmente, se instaura el matrimonio entre primos que encierra esta etapa incestuosa: de aquella pareja inicial descienden los huni kuin. El mito kaxinawa recogido por Capistrano de Abreu fue, como sabemos, uno de los relatos incluidos en el Rondó del Caetetu, del primer volumen de Mitológicas, que, a partir de mitos tenetehara, mundurucú y kayapó, consagra el pecarí como transformación de malos cuñados. En rigor el pecarí kaxinawá se encuentra en los antípodas de ese significado: se convierte en tal como protesta ante una conducta antisocial - embrionariamente incestuosa, como se ve después. En la versión kaxinawá, como hemos visto, la soltera impenitente se convierte en guardiana de una caja de tabaco de la que saldrá una especie de hijo/esposo. En la versión yawanawa ella se 
limita a comunicar lo ocurrido a los seres humanos. Pero hay otro mito yawanawa que trata de esa caja de tabaco:

«La acción transcurre en un tiempo en que « aún no había nada, pero ya existían las personas ». Nos presenta las aventuras un tanto extravagantes de un grupo de muchachos que viven junto a un viejo poco sociable. Un día llegan a quitarle la mujer, pero él no se inmuta. Sale con sus flechas hasta una encrucijada y espera hasta ver pasar un hombre de otra tribu. Lo mata, corta su cabeza y extrae de sus entrañas el reko ${ }^{15}$. Lleva esos trofeos hasta la aldea y los muestra a todos diciendo « esto es nawa, enemigo; no esos tapires que vosotros matais haciendo fiesta y diciendo que habéis matado gente; yo sí que sé matar nawa». Los jóvenes se atemorizan y le devuelven su esposa. El viejo guarda el reko del muerto en una bolsa tejida de palma y lo cuelga del techo de la cabaña. De la caja salen extraños ruidos « como de reloj »; el viejo la examina repetidamente, y cada vez encuentra un sombrero hecho de pluma, pelo o piel de algún animal (isko japó, shawa arara, runu boa, yawa pecarí, kama jaguar, shane, paka taboca, ushu garza). Después, la caja cae y revienta, y de cada sombrero sale una multitud de gente, de la tribu correspondiente a cada uno de los sombreros, iskonawa, shawanawa, rununawa, etc.). El viejo debe enseñar a los recién llegados cómo deben obrar, especialmente el uso de las armas. » (Carid Naveira 1999, pp. 166-169) ${ }^{16}$.

Ese mito del «origen de las tribus » reproduce la cuidada organización del mito del origen de los pecaríes en su versión yawanawa: en episodios prolijamente repetidos, distintas variedades humanas van apareciendo - correspondiendo a los principales grupos protagonistas de la historia yawanawa - cada una de ellas definida por su " sombrero » hecho de la piel de un animal. Como en el mito kaxinawá asistimos a una diferenciación de hombres y animales de caza - por el divorcio entre animales de hecho y humanidad verdadera, o entre la caza y la guerra - originada por conductas erróneas en relación al matrimonio: la negativa a casarse o el abuso de la paciencia del viejo.

Ya nos referimos al principio al uso frecuente de la tropa de pecaríes como metáfora de la humanidad social - comparable, a pesar de la diferencia de connotaciones, con el papel jugado en el mundo occidental por los enjambres de abejas o de hormigas. Si hay algún común denominador entre todas las narraciones hasta aquí comentadas, es sin duda la convicción de que es la instabilidad o la violación de las buenas maneras matrimoniales la que garantiza la frontera entre humanos y animales. Aunque esa moraleja vale para una larga serie de mitos protagonizados por animales muy diversos, los pecaríes ofrecen la particularidad de ilustrar, por decirlo así, una «doble articulación » de la sociedad humana: por fuera marcan (como en el mito kaxinawa) su divorcio de lo animal y por dentro (como en el yawanawa) las relaciones entre la parte y el todo. Los tres grupos cuyos mitos hemos reseñado aquí mueven de modo muy diferente esa articulación, según quieran individualizarse dentro del conjunto nawa (kaxi), subrayar la línea que une las diversas categorías (étnicas o zoológicas) a su origen (yawa) o las dudosas transacciones entre esas mismas categorías, haciendo abstracción de su origen (yami).

Ritos cinegéticos y mitos chamánicos

Aparte de los mitos a los que nos hemos referido en primer o en segundo plano, podemos encontrar en la bibliografía sobre las tierras bajas numerosas referencias a una serie de prácticas que se sitúan en un terreno común entre técnica y ritual de caza, y que nos ayudan a ampliar nuestro contexto. Rival (1996) describe así la caza de los pecaríes entre los huaorani como un modelo diametralmente opuesto a la caza más común de animales menores con cerbatana. Caza colectiva, no planificada sino decidida 
al azar por la aparición de un bando de pecaríes, y realizada a punta de lanza en el clima violento propio de la guerra. Algo muy semejante se registra para los kayapó (Txucarramãe y Stout 1990, p. 231) donde el arma escogida es la borduna (maza, arma guerrera por excelencia) y el grupo participa también en pleno, incluyendo a veces a las mujeres. La caza de los pecaríes es organizada como una guerra, y esa equivalencia se confirma a la inversa cuando es la caza la que proporciona su modelo a la guerra. Los araweté (Viveiros de Castro 1986, p. 208) se refieren a una técnica guerrera de sus vecinos kayapó consistente en arrinconarlos en un cercado, método que ellos por su parte aplican a la caza de los pecaríes, y que es precisamente aquél sugerido en los mitos tupí y gê sobre el origen de los cerdos salvajes analizados por Lévi-Strauss (1968 (1964), p. 91). Volviendo a los datos pano encontramos algunos rituales-juegos que evocan las técnicas de caza que acabamos de reseñar, y que introducen recortes de género en su ejecución. Uno de ellos es un juego yawanawa - conocido también por otros pano vecinos, como los katukina de la misma Terra Indígena Alto Río Gregorio en que los hombres, embadurnados de barro y entrechocando mitades de coco para imitar el batir de las mandíbulas del animal, salían de la selva limítrofe atacando a las mujeres de la aldea, revolcándose con ellas en el barro y tal vez en algún caso violándolas. Otro juego, esta vez sharanahua, es descrito así1 ${ }^{17}$ :

« los hombres se transforman en guanganas (pecaríes) y las mujeres los cazan [...] Un rumor creciente rodea al poblado. Gritos, gruñidos y sonar de dientes anuncian la proximidad de los hombres guanganas, que se mueven en grupo, con el cuerpo cubierto del barro de la collpa, llevando sobre la espalda hojas de yarina y chapaja, que recuerdan las cerdas del animal. Las mujeres cogen arcos y flechas y salen a su encuentro [...] rodean la manada y la sorprenden [...] Las guanganas huyen, pero muchos hombres quedan en el suelo atrapados por las mujeres, otros escapan heridos y muchos se quejan por los golpes recibidos [...] de las flechas sin punta. Siguiendo el juego, las mujeres intentan amarrar la pieza cobrada y llevarla a la espalda hasta el poblado. » (Torralba 1986, p. 66).

16 Sean los kayapó cazando Araweté-pecaríes, sean las mujeres sharanahua cazando pecaríes humanos, tenemos aquí un conjunto de rituales que no sólo se refieren a un mito sino que, en gran medida, lo representan; detalles como el de las flechas romas evocan de hecho aquellas explicaciones (a la Lord Raglan) del mito como descripción del ritual. Todos ellos manifiestan una cierta cualidad de trompe l'œil ${ }^{18}$, semejante a la de las gotas maravillosas que convertían el lodo en chicha: hombres-pecarí se disfrazan de pecaríes que, por debajo de su piel, son hombres; o si no, hombres guerrean contra pecaríes como si estuviesen cazando hombres. En cualquier caso, rituales en que la reversibilidad de la perspectiva se ofrece " a simple vista », no en un tiempo mítico ni con la ayuda de recursos chamánicos.

17 En contraste con estos rituales o métodos de caza o guerra "directa », hay todo un grupo más de discursos o mitos sobre los pecaríes que, aunque también referidos a la caza, se esfuerzan por presentar ésta como una actividad necesariamente mediada. Aparece un dueño de los animales, o una Madre de los animales, que los representa y en ocasiones los guarda en cobijos bajo la tierra o en el cielo ${ }^{19}$. En las versiones más sofisticadas (por ejemplo en el área tukano, $c f$. Arnhem 1996) la caza sólo es posible por la acción de un chamán que comercia con el dueño de los pecaríes, ofreciendo almas de su propia gente a cambio de las piezas de caza. La equivalencia « caníbal » es en último término la misma que se dibujaba en los rituales antes expuestos, pero la presencia del chamán la convierte en una equivalencia indirecta. Para llegar a ese resultado, el chamán tiene que convertirse en un mal cazador o en un abstinente. En el relato 
kaxinawá que Capistrano de Abreu titula «O feiticeiro e os porcos (4606-4627) 》se cuenta cómo un hechicero consigue engañar a los cerdos salvajes (invitándolos a comer las frutas maduras de su aldea) llevándolos así a una trampa mortal y saciando el hambre de su gente. Mientras la matanza tiene lugar, el hechicero se recoge en su hamaca. Pide un pedazo de carne, pero no consigue tragarla; se ahoga y tiene que escupirla. El tipo de hechicero que aquí aparece es el caracterizado por Deshayes (1992), Lima (1996) o Vilaça (2000) ; consigue dialogar con el mundo animal, pero esta habilidad le impide matar o comer seres con los que ha establecido relaciones de intercambio o identidad - el chamán es panemo o está relativamente condenado al ayuno, como el protagonista de Yawavide, su alter ego ${ }^{20}$. Eventualmente se entiende que por eso mismo el chamán es un célibe o un esposo defectuoso, afín al cazador sin suerte o a la novia difícil de los mitos. Comparando esa mediación con la inmediatez sugerida por los rituales, debemos pensar que unos y otros no son simplemente expresiones equivalentes del mismo mensaje. Un mito, un sueño, una técnica de caza, un ritual, el discurso de un chamán, suponen modos diferentes de distribución del saber simbólico y eventualmente efectos de realidad diferentes: así la falta de rituales de los yaminawa y su relativa riqueza entre los yawanawa, y la relación inversa que se observa en cuanto a las narraciones «de transformación» pueden no ser lagunas abiertas al azar. La chamanización creciente del sistema simbólico ayuda a generalizar la noción perspectivista, que pasa, como después diremos a respecto de los yaminawa, de aplicarse a dos o tres animales cruciales a servir como sistema general de interpretación. Pero al mismo tiempo la hace menos tangible, más especulativa. En último término, puede jugarse con valores de realidad diferentes para un mismo símbolo: matar animal o matar enemigo pueden ser la misma o diferente cosa según el momento ${ }^{21}$. Animismo y naturalismo no están así aislados en el interior de narrativas diversas sobre el mundo: pueden alternarse en el manejo de un mismo conjunto de símbolos.

Los pecaríes y el indigenismo pos-moderno

Basta conocer superficialmente la historia reciente de los pueblos indígenas del Acre para percibir que esas operaciones aparentemente miríficas que estamos describiendo no están en modo alguno alienadas de la política y la práctica más cotidianas. La organización social de los kaxinawá-huni kuin ha sido descrita (Keifenheim 1992) como una sabia combinación de filtros que les permite mantener una coherencia étnica y una relación prudente con los blancos por un lado y con los otros grupos indígenas; una cuidadosa combinación de valorización ideológica de la exogamia realizada en el marco de un repliegue endogámico. Aunque el término Huni Kuin (" gente legítima » o " gente de verdad» tenga sus equivalentes en todas las lenguas indígenas, para los kaxinawá parece significar algo bastante diferente; hemos reseñado aquí el que puede considerarse mito de origen de esa noción. En cuanto a los yaminawa - no por acaso una especie de negativo lógico de los kaxinawá - se ha puesto siempre de relieve la absoluta falta de ese tipo de resguardo: la continua fragmentación de sus grupos (que corresponde, claro está, a una recomposición igualmente continua pero siempre fuera de escena), sus migraciones suicidas hacia la periferia de las ciudades y en suma su fatal atracción hacia el mundo de los blancos. Ambas actitudes casan muy bien con las cosmologías aquí expuestas: en un caso, un incesto que sirve como "petición de principio » de la « humanidad legítima » o, si así lo queremos, de la identidad étnica; en el otro, la separación entre narrativas de la alianza y narrativas de origen - como hemos dicho, la diferenciación de los grupos yaminawa excluye la conciencia de la 
recomposición simultánea que ella supone. La configuración de los mitos fundamenta, o por lo menos hace coro a la reestructuración étnica. Vamos a examinar más de cerca el caso yawanawa, que en cierto sentido es un compromiso entre los dos anteriores. En su forma actual los yawanawa son el resultado de la articulación de un sin número de pequeños grupos - principalmente pano - que se dio en una fase epigonal del gran ciclo del caucho, cuando la economía de los seringales perdió su atractivo mundial y pasó a apoyarse más en los recursos locales, entre ellos la mano de obra indígena. Un grupo ligado al seringal fue anexionándose otros, por conquista o sujeción o por alianzas matrimoniales que no siempre se distinguían claramente de lo anterior, y que en muchos casos incluían familias blancas o mixtas. A principio de los años ochenta el grupo vivía bajo la égida de una misión fundamentalista norteamericana y la mayoría de sus miembros eran en mayor o menor medida cristianos, cuando en el cauce de un cambio general en la política indígena e indigenista brasileña un joven jefe optó, a mediados de esa década, por expulsar a los misioneros y entablar una serie de alianzas con sectores indigenistas no oficiales y empresas del eco-business. A diferencia de los anteriores, esos nuevos aliados favorecían los discursos y prácticas tradicionales - o tradicionalistas. Los yawanawa son ahora un grupo no particularmente numeroso (su número, cerca de 500, está muy próximo del de los yaminawa) y muy consciente de su diversidad de origen, pero considerablemente cohesionado - a diferencia del caso yaminawa, en que esa diversidad se actualiza constantemente. Ese conglomerado es el que responde al nombre "yawanawa " por mucho que, según ellos mismos suelen repetir, los yawanawa "legítimos » sean una ínfima minoría dentro del grupo, que coincide, por cierto, con la familia del mayor especialista vivo en cuestiones chamánicas y rituales. Nada puedo decir sobre las causas de tal elección, pero ella tiene sus consecuencias. Los hombres-pecaríes del Alto Río Gregorio gustan de hacer exégesis políticas de su etnónimo, subrayando su unidad y su fortaleza común, y comparando esa virtud cívico-natural con la disgregación de otras tribus, por ejemplo - cómo no los yaminawa. Esa convicción totémica es muy adecuada para un pueblo que enfatiza su tradicionalidad y su indianidad como estrategia cara a la sociedad blanca, pero es más que un signo diacrítico. El modelo de los pecaríes es invocado al explicar gestos y pasos de la suite de danzas del Mariri o Saiti (pieza fundamental de la expresión étnica yawanawa). Algunos yawanawa, según se nos dijo, habían deliberado sobre la necesidad de dejar de comer carne del animal epónimo: las potencialidades ordenadoras y significativas del símbolo son decididamente exploradas. Lo que puede ser más revelador es que entre los juegos/danzas tradicionales que se engloban ahora bajo el título común de Saiti o Mariri hubo por lo menos uno que fue excluido por ser considerado inconveniente: nada menos que el juego de los pecaríes, al que nos hemos referido anteriormente, y de cuya violencia se temía que tuviese resultados negativos para la buena convivencia. Aunque haya buenas razones para la higienización de las prácticas primitivas de un grupo que ha establecido fuertes alianzas con sectores ilustrados de la sociedad global, el caso es que esa exclusión revela la misma inclinación de las versiones yawanawa del mito: seleccionar del acervo simbólico los valores totémicos - las analogías entre lo animal y lo humano, el potencial clasificatorio - y neutralizando por el contrario la dimensión "animista", o por lo menos sus expresiones rituales más fuertes.

En conclusión: mitologías y cosmologías

19 Al yuxtaponer los mitos sobre los pecaríes, lo que resalta en un primer momento es su perfecta articulación, la claridad con que unos desarrollan elementos embrionarios de 
otros, o iluminan sus aspectos oscuros - un buen ejemplo del diálogo entre mitos que supone la teoría levi-straussiana. No entremos aquí en especulaciones generativas - la precedencia entre unas y otras versiones, o la reconstrucción hipotética de narraciones previas, asuntos quizás interesantes pero sin duda muy difíciles. Lo que nos interesa repetir en esta conclusión es que las mitologías concretas suponen selecciones diferentes de ese acervo común, que guardan una cierta homología con los rumbos diversos tomados por esos diversos pueblos a partir de un pasado común no tan distante. Hemos dicho algo sobre identidades étnicas, y creo que del mismo modo se podrían establecer relaciones, por ejemplo, entre mitologías locales y variantes locales del chamanismo.

Pero recapitulemos la cuestión en lo que se refiere a los yaminawa. Los yaminawa, como vimos desde el principio, separan la transformación de un grupo humano en una manada de queixadaes de la peripecia del cazador, que en otras versiones están ligados. El tipo de narración que cada una de ellas puede representar ha tenido una suerte muy diferente en la tradición oral. Me inclinaría a decir que los mitos "de origen» desaparecen o se debilitan en la narrativa yaminawa a favor de relatos con un cariz novelesco o historicista. Ese desinterés por los discursos totalizadores parece resultado de la misma inclinación que determina la « desaparición » o decadencia del dualismo comentado por Townsley para los yaminawa del Perú - o su reducción a una interpretación idiosincrática como la que fue resumida en páginas anteriores ${ }^{22}$. En contraste es enorme la vitalidad de aquellas narraciones en que un protagonista humano emprende alguna aventura con un animal, que muchas veces incluye el matrimonio. Los yaminawa me contaron una larga serie de estos relatos, que implicaban los animales más variados (ardillas, sapos, tórtolas, monos, anacondas...), lejos de la limitación a algunas pocas especies de animales «con espíritu » que se observa en otras mitologías. No quiero fundar en ese aspecto un carácter específico de la mitología yaminawa - a fin de cuentas, ese tipo de aventuras son demasiado comunes en la mitología poco escudriñada de las tierras bajas - sino recalcar que esa variedad se daba en virtud de una fórmula capaz de reproducirse ad infinitum: no se trata ya de mitos de los que puede inferirse alguna constante cosmológica, sino de una cosmología produciendo, por así decirlo, mitos en serie. No creo que esa producción de narraciones sobre los amoríos desgraciados entre las especies se pueda separar de la producción, asimismo en serie, de subgrupos «nawa » con nombres de animales, alternativamente relacionados por la hostilidad o la alianza, que constituye el conjunto yaminawa. La etnonimía y la organización social yaminawa tienen, sí, sus raíces en la mitología.

«Cosmología » es un término frecuente en la literatura etnológica. A veces se utiliza con un significado bastante concreto, que tal vez se vería mejor servido por el término " cosmografía »: un discurso sobre la forma y el origen del universo, sobre la variedad y el valor de sus regiones. Pero en otras parece más bien un equivalente vago de nociones también vagas, como " pensamiento » o « filosofía » (o « lógica », o " gramática », etc.): un régimen regulador de categorías, valores, axiomas, etc., que podemos identificar como equivalente y diferente de otros pensamientos o filosofías - como los nuestros, a los que raramente aplicamos el rótulo de " cosmologías ». Es en este último sentido que la palabra nos interesa aquí. Los etnólogos dados a la cosmología pueden dividirse en dos partidos: aquellos que encuentran en su camino un cosmólogo nativo cuyas elaboraciones obtienen curso legal en la bibliografía y aquellos otros que, a solas con un discurso fragmentario o con un pueblo de talante poco hablador, tienen que participar más activamente en la deducción de esa cosmología. Hay quienes prefieren el 
cosmólogo nativo al cosmólogo visitante, o viceversa, pero en ambos casos la relación entre cosmología y mitología parece en buena medida arbitraria, legitimada sólo por la autenticidad cultural del uno o científica del otro. Lo que vengo a sugerir en las páginas anteriores es, por el contrario, que el buen cosmólogo, nativo o no, ejerce una autoridad limitada. Las cosmologías se encuentran pre-formuladas no exactamente en la estructura del sistema simbólico, sino en el uso que se hace de él: agrupando o separando episodios míticos, seleccionando narraciones o rituales, formulando exégesis o eludiéndolas, definiendo versiones canónicas de determinados postulados y permitiendo una elaboración libre con respecto a otros, introduciendo una jerarquía de géneros narrativos, enfocando las figuras mediadoras o relegándolas a la periferia. A una primer ordenación - digamos « estructural » - de lo simbólico se sigue una segunda ordenación - digamos "pragmática» o "performativa - que puede resultar en visiones totémicas, naturalistas o animistas, en ontologías del ser o del devenir. Las cosmologías interpretan los símbolos, pero obedecen a las mismas operaciones de transformación y recombinación que los regulan a ellos.

\section{BIBLIOGRAFÍA}

\section{ABREU João Capistrano de}

1941 [1914] Rã-txa hu-ni-ku-i: Grammatica, textos e vocabulario Caxinauás, Edição da Sociedade Capistrano de Abreu.

\section{ÁLVAREZ Ricardo}

1960 Los Piros. Leyendas, mitos, cuentos, Instituto de Estudios Tropicales Pío Aza.

\section{ARNHEM Kaj}

1996 « The cosmic food-web: human-nature relatedness in the Northwest Amazon ", in P. Descola y G. Pálsson (eds), Nature and Society. Anthropological Perspectives, European Association of Social Anthropologists, Routledge, London, pp. 185-204.

\section{CALAVIA SÁEZ Oscar}

19950 nome e o tempo dos Yaminawa. Etnologia e historia dos Yaminawa do Alto Rio Acre, tese de doutoramento em antropologia, DA FFLCH, Universidade de São Paulo.

1996 « Historiadores selvagens: algumas reflexões sobre história e etnologia », Antropologia em Primeira Mão, 18, PPGAS, Florianópolis.

2000 « Mythologies of the Vine », in L. E. Luna y S. White (eds), Ayahuasca Reader, Synergetic Press, Santa Fe, pp. 36-40.

\section{CARID NAVEIRA Miguel}

1999 Yawanawa: da guerra à festa, dissertação de mestrado, PPGAS-UFSC, Florianópolis.

D’ANs André Marcel

1975 La verdadera Biblia de los Cashinahua, Ed. Mosca Azul, Lima.

DESCOLA Philippe

1996 « Constructing natures: symbolic ecology and social practice », in P. Descola y G. Pálsson 
(eds), Nature and Society. Anthropological Perspectives, European Association of Social Anthropologists, Routledge, London, pp. 82-102.

1998 « Estrutura ou sentimento: a relação com o animal na Amazônia », Mana, 4 (1), pp. 23-45.

DEscola Philippe y Gísli PÁLsson (eds)

1996 Nature and Society. Anthropological Perspectives, European Association of Social

Anthropologists, Routledge, London.

DESHAYEs Patrick

1992 « Paroles chassées. Chamanisme et chefferie chez les Kashinawa ", Journal de la Société des Américanistes, LXXVIII-2, pp. 95-106.

DESHAYES Patrick y Barbara KEIFENHEIM

1982 La conception de l'autre chez les Kashinawa, thèse de doctorat, université Paris VII, Paris.

ERIKSON Philippe

1993 « Une nébuleuse compacte: le macro-ensemble Pano », L’Homme, 126-128, pp. 45-58.

1996 La griffe des aïeux. Marquage du corps et démarquages ethniques chez les Matis d'Amazonie, Peeters, Paris.

FRANK Edwin

1994 « Los Uni/Cashibo », in F. Santos y F. Barclay (eds), Guía etnográfica de la Alta Amazonía II, FLACSO/IFEA, Quito.

IHERING Rodolpho von

1940 Dicionário dos Animais do Brasil, Secretaria de Agricultura, Indústria y Comércio do Estado, São Paulo.

\section{KEIFENHEIM Barbara}

1992 «Identité et altérité chez les Indiens Pano », Journal de la Société des Américanistes, LXXVIII-2, pp. 79-93.

KENSINGER Kenneth M.

1995 How real people ought to live. The Cashinahua of Eastern Peru, Waveland Press, Prospect Heights, Illinois.

\section{LAGROU Elsje Maria}

1998 Caminhos, duplos e corpos. Uma abordagem perspectivista da identidade e alteridade entre os Kaxinawá, tesis de doctorado en Antropología social, Universidad de São Paulo, Sãn Paulo.

LÉVI-STRAUSS Claude

1968 [1964] Mitológicas I - Lo crudo y lo cocido, Fondo de Cultura Económica, México.

LIMA Edilene Coffaci de

2000 Com os olhos da serpente: homens, animais e espíritos nas concepções Katukina sobre a Natureza, tesis doctoral, Universidade de São Paulo.

LIMA Tânia Stoltze

1996 « O dois e seu múltiplo: reflexões sobre o perspectivismo em uma cosmologia Tupi », Mana, 2 (2), pp. 21-48.

LUNA Luis Eduardo y Steven wHITE

2000 Ayahuasca Reader, Synergetic Press, Santa Fe.

RIVAL Laura

1996 « Blowpipes and spears: the social significance of Huaorani technological choices », in 
P. Descola y G. Pálsson (eds), Nature and Society. Anthropological Perspectives, European Association of Social Anthropologists, Routledge, London, pp. 145-164.

ROE Peter G.

1982 The Cosmic Zygote: Cosmology in the Amazon Basin, Rutgers University Press, New Jersey.

TORRALBa Adolfo

1986 Sharanahua, Secretariado de Misiones Dominicanas, Madrid.

TOWNSLEY Graham

1989 Ideas of order and patterns of change in Yaminahua society, Ph.D., University of Cambridge.

TXUCARRAMÃE Megaron y Mick STOUT

1990 « A expedição venatória dos Kayapó e animais importantes », in Ethnobiology: Implications and Applications, Volume 1, Belém.

VILAÇA Aparecida

1998 «Fazendo corpos: reflexões sobre morte e canibalismo entre os Wari' à luz do perspectivismo ", Revista de Antropologia, 41 (1), pp. 9-67.

2000 « O que significa tornar-se outro? Xamanismo e contato interétnico na Amazônia », Revista Brasileira de Ciências Sociais, 15 (44), pp. 56-72.

VIVEIROS DE CASTRo Eduardo

1986 Araweté: os deuses canibais, Jorge Zahar ed., ANPOCS, Rio de Janeiro.

1996 « Os pronomes cosmológicos e o perspectivismo ameríndio », Mana, 2 (2), pp. 115-144.

2000 « Atualização e contra-efetuação do virtual na socialidade amazônica: o processo de parentesco », ILHA, 2 (1), pp. 5-46.

\section{NOTAS}

1. Este artículo deriva en su mayor parte de un curso impartido en el Programa de PosGraduación en Antropología Social de la Universidad Federal de Santa Catarina, en Brasil. Quiero agradecer aquí la colaboración de los participantes: Acacio Piedade, Maria Ignez Cruz Mello, Liliane Brum Ribeiro, Lisiane Lecznieski, Giselle Camargo, M. Cristina Pereira, Hévila Peres da Cruz, Fernando Bitencourt, Nara Magalhães e Deise Montardo.

2. Trato aquí principalmente de grupos de lengua pano situados a ambos lados de la frontera entre Brasil y Perú. Los datos yaminawa derivan de mi trabajo de campo, realizado entre 1992 y 1993 en la aldea Cabeceiras do Rio Acre (Calavia 1995). En ocasiones posteriores trabajé en la ciudad con colaboradores indígenas que tradujeron o comentaron los mitos. En 1998 permanecí cerca de un mes en la Terra Indígena yawanawa Alto Río Gregorio ; a los datos recogidos durante ese periodo se suman aquí otros cedidos por Miguel Carid y Laura Pérez Gil, que trabajaron en aquella aldea durante seis meses.

3. Ese pájaro « que hace queixada » - ésa sería la traducción de su nombre - no existe fuera de esta narración. Los protagonistas del mito, en ésta y en otras versiones, lo identifican erróneamente con aves como el inhambú o el jacú.

4. Cf. otro tipo de relación entre queixada y caetetu en Lévi-Strauss (1968 [1964], p. 90); en los mitos tupí y gê, el caetetu es la caza por antonomasia, sólo la queixada es transformación de un ser humano. 
5. Son conocidos en la literatura especializada como yaminawa.

6. O incluso más allá: un mismo individuo puede presentarse como mestizo de marinawa y mastanawa, por ejemplo, o reivindicar tantas identidades como ascendientes sea capaz de recordar.

7. Cf. los sufijos -ineru entre los piro arawak, -djapá entre los katukina o-madiha entre los culina.

8. El término kaiwo no se usa exclusivamente en esta acepción, pudiendo aplicarse también a otras agrupaciones, como las designadas por los etnónimos. Noko kaiwo ( " nuestra gente ») connota sin embargo ancestralidad y aparece esencialmente en discursos sobre el pasado, en contraste con un término como noko yura (nuestro cuerpo), que se refiere más bien a una comunidad « en acto ».

9. Esa complejidad puede comprobarse al examinar de cerca el tabú alimentario que ella implica: va de una caza apreciada y relativamente frecuente (los pecaríes) a otra a la vez poco interesante y sumamente rara (las aves de altura) pasando por animales que nadie puede comer (jaguar o gamba) y por un grupo mixto que reúne tabúes comunes y alimentos muy populares (la anaconda y el mandí, respectivamente). Lima (2000, pp. 69-70) y Lagrou (1998, pp. 57 y 90) exponen una clasificación de enfermedades a partir de la analogía de sus síntomas con el comportamiento de algunos animales, cuya carne debe ser evitada en determinadas circunstancias. En esos casos, el argumento usado parece ser opuesto al que aquí nos ocupa: la abstinencia de una carne intenta evitar la « confusión » con ese animal, en lugar de ser consecuencia de la identificación con él.

10. En el transcurso de mi investigación el jefe del grupo se separó de sus seguidores, yéndose a vivir en la ciudad. Fue substituido por otro, que no contaba sin embargo con el apoyo de una parte del grupo. La aldea se deshizo no mucho después de mi partida. 11. Ese desequilibrio, por lo demás, evoca el diagnóstico (Viveiros de Castro 2000) de la afinidad como algo « dado » previamente a la sociedad, a partir de lo cual cabe, si hay suerte, « construir » la consanguinidad.

12. Descola (1996) y Viveiros de Castro (1996) dan versiones diferentes del término animismo ; para el primero, el animismo resulta de una proyección de la sociedad sobre la naturaleza, constituyéndose en un reverso del totemismo ; para el segundo, el animismo es por así decir perpendicular al totemismo, postulando relaciones y no, como éste, correlaciones o analogías ; en estas páginas el término animismo es usado prioritariamente en este segundo sentido.

13. La incidental identificación del ave yawayawaiká con el jacú puede reforzar algunas de las connotaciones de la queixada: ave gregaria, el jacú sólo dispersa sus nutridos bandos en la época de la incubación (von Ihering 1940, p. 420).

14. El temprano estudio de Capistrano de Abreu sobre los kaxinawá (Abreu 1941, publicado inicialmente en 1914) ha contribuido de forma decisiva para hacer de ellos un modelo dentro de la etnología pano. Pero ha tenido por lo menos una consecuencia dudosa, la de fijar un corpus de mitos que autores posteriores han citado repetidamente como relatos canónicos, dejando poco espacio a nuevas versiones. La pertinencia de esos mitos en relación a la situación actual de los kaxinawa debe tomarse así con alguna prudencia.

15. Reko es un término de difícil traducción, que parece aludir siempre a un « núcleo duro » de la persona que se localiza materialmente en el estómago. Los yaminawa a veces lo glosaban como « raíz » - véase, por ejemplo, en el compuesto yawareko antes 
citado. Informantes yawanawa lo identificaban con una piedra como la que se encuentra en las entrañas de algunos animales.

16. Una versión sharanahua (Torralba 1986, p. 7) es muy semejante a la parte aquí seleccionada del relato Yawanawa, narrando la salida de la caja de numerosas tribus; un mito yaminawa que también comienza con el reko guardado en la caja se dedica al otro aspecto de la narración, el aprendizaje de los jóvenes díscolos que no parecen saber la diferencia entre jugar y matar, o entre guerra y caza. Erikson $(1996$, p. 76$)$ trata de esos mitos de « eclosión ", comunes entre los matís y etnias vecinas ; en ese caso, la diversidad étnica se cifra en la diversidad de los receptáculos originales, siempre llamados « huevos » $(t u)$, se trate de calabazas, vasijas de barro o « huevos » de armadillo.

17. En ambos casos, el juego de los pecaríes está - en rigor estaba - incluido en una suite de juegos en que los hombres se transformaban en diversos animales: monos, ratones, mosquitos... En ambos casos, también, el juego de los pecaríes era con mucho el más dramático y complejo.

18. Para ser fieles a la gramática perspectivista, sería mejor decir tourne l'œil ; no es una ilusión, sino el otro lado, lo que se muestra.

19. Un mito piro (Álvarez 1960, pp. 152-153) coordina esa conexión chamánica con el énfasis en la clasificación de los mitos yawanawa: una Madre de las huanganas guarda en sus corrales ctónicos todas las razas de pecaríes - cada una con una característica que la asemeja a un grupo humano; un hechicero, robando las trompetas con que la Madre daba órdenes a sus rebaños, consigue soltarlos y ponerlos al alcance de los seres humanos.

20. Quedará para otra ocasión contrastar esa abstinencia del chamán con otras conductas amazónicas relativas a la domesticación de animales (Descola 1998) y su eventual uso como víctima sacrificial (Roe 1982, pp. 93-112 ; Frank 1994).

21. Recordemos cómo el ritual antropofágico funerario wari' (Vilaça 1998) oscila constantemente entre la identificación y la diferenciación entre el cadáver y la caza: el cuerpo es lo primero para los consanguíneos y lo segundo para los afines, pero la espera - y por tanto la putrefacción - se impone para debilitar esta segunda identificación. 22. En un trabajo anterior (Calavia 1996) expuse a partir de otros datos una interpretación semejante, comparando mitos cosmogónicos de otros pueblos pano con versiones yaminawa, en mi opinión « historificadas ». Por sutil y subjetiva que pueda ser la diferencia, no deja de tener algunos asideros bastante concretos, como por ejemplo en la ausencia casi total en la narrativa yaminawa de frases tópicas del tipo « $\mathrm{y}$ desde entonces hacemos así u ocurre tal cosa ». Esa cláusula aitiológica aparece, por el contrario, en narraciones paródicas - contadas comúnmente por mujeres y niños - que explican por qué los mosquitos están en todas partes o por qué el excremento humano huele mal. 


\section{RESÚMENES}

El rastro de los pecaríes. Variaciones míticas, variaciones cosmológicas e identidades étnicas en la etnología pano Debido a su carácter gregario, los pecaríes (Tayassu albirostris) son un motivo frecuente de reflexión sociológica en los sistemas simbólicos de la Amazonia. Este artículo analiza algunos mitos sobre pecaríes de pueblos de lengua pano - yaminawa e yawanawa - que usan ese animal como uno de sus emblemas grupales. A partir de un acervo mítico común estos grupos seleccionan y encadenan episodios de modos diferentes, en sintonía con diferentes modelos de organización e identidad. Propongo entender esta ordenación del material simbólico como base de la elaboración de las cosmologías locales.

La trace des pécaris. Variations mythiques, variations cosmologiques et identités ethniques dans l'ethnologie pano. En raison de leur caractère grégaire, les pécaris (Tayassu albirostris) sont un motif courant de la réflexion sociologique qui parcourt les systèmes symboliques de l'Amazonie. Le présent article analyse quelques mythes sur les pécaris chez des groupes de langue pano Yaminawa et Yawanawa -, mythes où cet animal est pris comme un emblème des groupes. À partir d'un fond mythique commun chacun, à sa manière, choisit des épisodes et les articule entre eux, en syntonie avec différents modèles d'organisation et d'identité. Je suggère que c'est cette mise en ordre des matériaux symboliques qui est à l'origine du développement des cosmologies locales.

0 rastro dos porcos do mato. Variações míticas, variações cosmológicas e identidades étnicas na etnologia pano. Devido ao seu caráter gregário, os porcos do mato (Tayassu albirostris) são um motivo freqüente da reflexão sociológica nos sistemas simbólicos da Amazônia. o presente artigo analisa alguns mitos sobre os porcos do mato de grupos de língua pano - Yaminawa e Yawanawa - que consideram este animal como um dos seus emblemas. A partir de um fundamento mítico comum, cada um desses grupos escolha episódios e os articula entre si em sintonia com vários modelos de organização e de identidade. Esse arranjo do material simbólico é, ao meu ver, a base de elaboração das cosmologias locais.

\section{ÍNDICE}

Mots-clés: totémisme, mythologie, cosmologie, animisme

Keywords: cosmology, totemism, mythology, animism

Palabras claves: cosmología, mitología, animismo

Índice geográfico: Pano, Yaminawa, Yawanawa, Brésil, Amazonie, Pérou

Temas: Ethnologie

\section{AUTOR}

\section{OSCAR CALAVIA SÁEZ}

PPGAS, Universidade Federal de Santa Catarina, Brésil 